\title{
LA OBLIGACIÓN DE TOMA DE CONCIENCIA: DEFICIENCIAS DEL SISTEMA DE SEGURIDAD SOCIAL Y DE LOS ESTABLECIMIENTOS DE LARGA ESTADÍA PARA EL ADULTO MAYOR
}

\author{
AWARENESS-RAISING: DEFICIENCIES OF THE SOCIAL \\ SECURITY SYSTEM AND LONG TERM \\ ESTABLISHMENTS FOR OLDER PERSONS
}

\begin{tabular}{|c|c|}
\hline \multicolumn{2}{|c|}{ ARTÍCULO INÉDITO DE INVESTIGACIÓN } \\
\hline CÓMO CITAR ESTE ARTÍCULO (CHICAGO) & 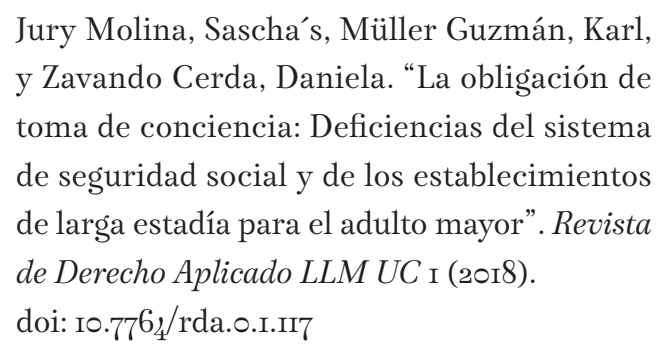 \\
\hline REVISTA DE DERECHO APLICADO LLM UC & $\begin{array}{l}\text { Número I } \\
\text { Julio } 2018 \\
\text { ISSN: } 245^{2-4344}\end{array}$ \\
\hline & $\begin{array}{l}\text { Recepción: } 22 \text { de junio, } 2018 \\
\text { Aceptación: } 23 \text { de julio, } 2018\end{array}$ \\
\hline
\end{tabular}




\section{Resumen}

Los adultos mayores constituyen un grupo de personas vulnerables que requieren de una especial regulación que respete y garantice sus derechos fundamentales. Ésta es una materia que adquiere actualmente mayor relevancia por el aumento de la población perteneciente a dicho grupo etario, así como por la aprobación de la Convención Interamericana sobre la protección de los derechos humanos de las personas mayores. Se destaca en dicho Convenio la consagración y regulación de la obligación de toma de conciencia, lo cual innova en la materia en relación con los demás tratados sobre derechos humanos.

Palabras claves: personas mayores, derechos humanos, tratados internacionales, toma de conciencia, seguridad social

\section{Abstract}

Older people are a vulnerable group who require special regulations respecting and guaranteeing their fundamental rights. This is a matter that is currently becoming more relevant due to the aging of the population as well as the approval of the Inter-American Convention on the protection of the human rights of older persons. The Convention establishes the recognition and regulation of awareness-raising, which is an innovation in respect to other human rights treaties.

Keywords: elderly people, human rights, international treaties, awareness raising, social security 
Sascha's Jury Molina

Universidad de Viña del Mar

Escuela de Ciencias

Jurídicas y Sociales

Viña del Mar, Chile

sascha.jury@uvm.cl

Universidad de Viña del Mar

School of Legal and

Social Sciences

Viña del Mar, Chile

sascha.jury@uvm.cl
Sascha's Jury Molina es Abogado, Universidad Andrés Bello y Magister en Derecho de la Empresa LLM , Pontificia Universidad Católica de Chile. Profesora de Derecho, Universidad Viña del Mar, Chile.

Sascha's Jury Molina is a lawyer from Universidad Andrés Bello, Master in Enterprise Law LLM from Pontificia Universidad Católica de Chile and a Law Professor at Universidad Viña del Mar, Chile.

\section{Karl Müller Guzmán}

Universidad de Viña del Mar

Escuela de Ciencias

Jurídicas y Sociales

Viña del Mar, Chile

karl.muller@uvm.cl

Universidad de Viña del Mar

School of Legal and

Social Sciences

Viña del Mar, Chile

karl.muller@uvm.cl
Karl Müller Guzmán es Abogado, Universidad de Valparaíso y Doctor en Derecho, Pontificia Universidad Católica de Chile. Profesor de Derecho, Universidad Viña del Mar, Chile.

Karl Müller Guzmán is a lawyer from Universidad de Valparaíso, $\mathrm{PhD}$ in Law from Pontificia Universidad Católica de Chile and a Law Professor at Universidad Viña del Mar, Chile.

\section{Daniela Zavando Cerda}

Universidad de Viña del Mar

Escuela de Ciencias

Jurídicas y Sociales

Viña del Mar, Chile

daniela.zavando@uvm.cl

Universidad de Viña del Mar

School of Legal and

Social Sciences

Viña del Mar, Chile

daniela.zavando@uvm.cl
Daniela Zavando Cerda es Abogado, Universidad Andrés Bello Magister en Asesoría Jurídica Fiscal-Mercantil y Laboral, Universidad de Sevilla, España. Profesora de Derecho, Universidad Viña del Mar, Chile.

Daniela Zavando Cerda is a lawyer from Universidad Andrés Bello, Master in Business Labor and Tax Advice from Universidad de Sevilla, Spain, and a Law Professor at Universidad Viña del Mar, Chile. 


\section{Introducción}

Sin la toma de conciencia de la situación actual de vulnerabilidad en la que se encuentran la mayoría de las personas de la tercera edad en nuestro país, no es posible garantizar efectivamente los derechos de los cuales son titulares. No es suficiente crear un catálogo de derechos y garantías destinadas a proteger en particular a las personas mayores, pues esto ya existe, sino que es necesario para lograr un real cambio reconocer e identificar sus variadas problemáticas e intereses de dicho grupo etario. De esa forma se logra contribuir a la eficacia de estas normas jurídicas ${ }^{1}$.

La ineficacia vinculada a la falta de toma de conciencia es un aspecto relevante a considerar al momento de analizar una determinada área del derecho, en este caso, la garantía a los derechos humanos de los adultos mayores. Dicha relevancia se manifiesta tanto en la consagración y regulación de la toma de conciencia como una obligación jurídica de conformidad al derecho internacional y nacional, como también por los profundos cambios que el aumento de la población de adultos mayores genera en la sociedad y, por ende, en el derecho.

El Estado de Chile, al ratificar y publicar el 7 de octubre de 2017 la Convención Interamericana sobre la protección de los derechos humanos de las personas mayores (CIDHPM), por medio del Decreto i62, asumió la obligación de desarrollar políticas públicas, planes y programas tendientes a garantizar el curso de la vida de las personas, desde el inicio de su existencia hasta la última etapa de su vida, con especial énfasis en la vejez. De esta manera, Chile ha adquirido jurídicamente una difícil y compleja tarea, que en la doctrina se ha identificado con la necesidad de recuperar el respeto al anciano y su valoración como un aporte y sustento para el desarrollo de una comunidad, gracias a la experiencia y sabiduría que pueden transmitir a las nuevas generaciones.

De esta manera, la Convención, junto con establecer obligaciones a los Estados que la ratifican, se identifica como un instrumento que permite abordar la problemática esencial que presenta este grupo etario de la sociedad, por medio de la toma de conciencia como una obligación novísima y adicional al deber respetar y garantizar los derechos humanos de las personas mayores.

1 En teoría se ha sostenido una absoluta separación entre validez y eficacia de las normas jurídicas, en el sentido de que la validez de las normas jurídicas no se ve afectada por su incumplimiento o ineficacia. A la vez, se ha sostenido la existencia de una relación entre ambos conceptos. En el derecho actual, y en los diversos ordenamientos jurídicos, no se acepta que la ineficacia o desuso afecte la validez de las normas jurídicas, esto es, que constituya una causal de terminación de la vida jurídica de una norma. Ver Agustín Squella Narducci, Introducción al Derecho (Santiago: Editorial Jurídica de Chile, 2000), $34_{4}^{6-349}$. 
En este orden de ideas, se destaca que efectivamente existen diversos aspectos que dificultan la observancia de los derechos de los adultos mayores, siendo uno de ellos la ineficacia de las normas jurídicas. Diversas son las razones que explican dicha ineficacia, sin embargo, tales razones tienen su fundamento en la toma de conciencia por parte del Estado, las organizaciones internacionales y de los individuos respecto de la realidad que viven los adultos mayores, sus problemas, sus intereses, así como del estatuto jurídico que los regula en forma particular.

De allí que resulta esencial conocer dicha realidad, particularmente en relación con la seguridad social y los Establecimiento de Larga Estadía para el Adulto Mayor (ELEAM), así como los elementos centrales de la regulación jurídica de la toma de conciencia. Todos estos aspectos se desarrollarán a continuación.

\section{r.Ineficacia de la regulación actual de los derechos humanos de los adultos mayores}

En el ámbito de las Organizaciones internacionales ${ }^{2}$, así como en la doctrina ${ }^{3}$, se ha destacado que uno de los problemas que enfrenta el respeto de los derechos humanos de los adultos mayores es la ineficacia de sus normas. Diversas son las razones que explican dicha ineficacia, pudiendo distinguirse entre razones de tipo general, en el sentido que no dice relación con un grupo de riesgo en particular y otras que efectivamente se explican preferentemente en relación con dichos grupos y, particularmente, con respecto a los adultos mayores.

A. Razones que explican la ineficacia de los Derechos Humanos de los adultos mayores.

- Con respecto a las razones genéricas se destacan las siguientes: la falta de conocimiento de los derechos humanos y de su consagración jurídica; la duplicidad de regulaciones; la existencia de normas genéricas o meramente programáticas; la debilidad del carácter sancionatorio y de control en relación con algunos cuerpos normativos, particularmente de los tratados acordados en el ámbito de las Naciones Unidas, en que los órganos internacionales de control de dichos tratados carecen de imperio para sancionar su incumplimiento; y por

2 Ver Consejo de Derechos Humanos de las Naciones Unidas, Informe resumido de la consulta sobre la promoción y protección de los derechos humanos de las personas de edad. Informe de la Oficina del Alto Comisionado de las Naciones Unidas para los Derechos Humanos. I de julio de 2013 . https://documents-dds-ny.un.org/doc/UNDOC/GEN/GI3/I53/29/PDF/GI3I5329.pdf.

3 Sandra Huenchuan, "Un paso adelante para los Derechos Humanos. La protección de las personas mayores en las Américas”, Anuario de Derechos Humanos I2 (20I6): 228. 
último, la vulnerabilidad de las personas, ya sean adultos mayores, niños, mujeres, discapacitados, migrantes, entre otros, los que tienden a ser objeto de abusos, maltratos y a que no se respeten sus derechos ${ }^{4}$.

- Las razones específicas en relación con la ineficacia de la garantía de los derechos humanos de los adultos mayores corresponden en primer lugar a que se considera a los adultos mayores como un lastre para la sociedad, como una realidad que afecta a otros, dejando de lado el respeto y aprecio por los ancianos que existía arraigado en diversas sociedades, particularmente en los pueblos indígenas u originarios $^{5}$. A su vez, pudiendo existir un conocimiento tanto de la realidad de los adultos mayores como de sus derechos, subsiste la falta de sensibilización o empatía para con los adultos mayores, lo cual dificulta su eficacia y reconocimiento universal ${ }^{6}$.

Por otra parte, los derechos humanos de los adultos mayores, en cuanto a su consagración en cuerpos normativos, es de reciente data. Es un derecho joven en el mundo, en América Latina y particularmente en Chile, lo que contribuye a su desconocimiento y por ende a su incumplimiento. Esto genera no solo el cuestionamiento sobre su real necesidad y por la duplicidad de normas ${ }^{7}$, sino que también suscita problemas relacionados con la interpretación de las normas jurídicas y de eventuales antinomias o colisiones normativas.

En estrecha relación con lo antes señalado, esta complejidad se traduce no solo en determinar el sentido y alcance de esos nuevos derechos, sino también, en determinar cuáles

4 Fabiola Lathrop, "Protección jurídica de los adultos mayores en Chile", Revista Chilena de Derecho $36, \mathrm{n}^{\circ} \mathrm{I},(2009): 85^{-88}$.

$5 \quad$ Ibid., 78.

6 Sandra Huenchuan, Perspectivas globales sobre la protección de los derechos humanos de las personas mayores, 2007-20I3 (Naciones Unidas, Comisión Económica para América Latina y el Caribe, 20I3): I6.

$7 \quad$ Ver supra nota 3, 232. En este sentido, se ha sostenido del listado de derechos humanos de los adultos mayores que en general no son más que una reiteración de los derechos humanos reconocidos en otros textos jurídicos, siendo solamente tres los que se pueden calificar como propiamente innovadores de este grupo etario o como derecho emergentes: derecho a la vida y a la dignidad en la vejez (art. 6), derecho a la independencia y autonomía (art. 7) y el derecho a los cuidados de largo plazo (art. I2). 
son las obligaciones del Estado en relación con tales derechos y la forma como se debe promover, respetar y garantizar su ejercicio y goce ${ }^{8}$.

Otro aspecto que afecta la eficacia de las normas jurídicas en esta materia dice relación con la complejidad de la regulación de ciertas temáticas vinculadas directamente con los derechos humanos de los adultos mayores como, por ejemplo, la regulación de los Establecimientos de Larga Estadía para el Adulto Mayor (ELEAM), la cual está sujeta a un régimen jurídico de derecho público y privado ${ }^{9}$. A su vez, éste es un ámbito que demuestra de una forma brutal la ineficacia de los derechos humanos de los adultos mayores, la cual está en estrecha relación con la falta de personal destinado a fiscalizar el funcionamiento de estos establecimientos.

Subsiste una desregulación y falta de coherencia en la regulación existente de esta materia. Así, por ejemplo, se menciona la incongruencia y discriminación que significa que se consagre una determinada edad para jubilar respecto de los hombres y otra para las mujeres, sin perjuicio del cuestionamiento que genera la existencia de la necesidad de jubilar ${ }^{10}$. Esto se aprecia especialmente en relación con los tres derechos humanos de los adultos mayores que se califican de emergentes, como son el derecho a la vida y a la dignidad en la vejez; el derecho a la independencia y autonomía; y el derecho a cuidados de largo plazo.

\section{B. Medidas que contribuyen a la eficacia de los Derechos Humanos de los adultos mayores}

De esta forma, identificados los diversos obstáculos que inciden en la eficacia de los derechos humanos de los adultos mayores, diversas son también las medidas que se han adoptado para superar estas dificultades que afectan la efectividad de tales derechos. Dichas medidas también se pueden clasificar en genéricas y específicas conforme al criterio ya señalado a propósito de la clasificación de los obstáculos que enfrenta el cumplimiento de estas normas.

8 Ver supra nota 3, 233. En estos tres derechos la Convención aporta nuevos elementos para establecer específicamente las obligaciones de los Estados respecto de las personas mayores. Por ejemplo, se prohíbe la discriminación por edad en la vejez; se indican los requisitos para que la persona mayor brinde su consentimiento libre e informado, y se obliga a los Estados a crear mecanismos para que la persona mayor manifieste de manera expresa su voluntad anticipada y las instrucciones respecto de las intervenciones en materia de atención en salud, incluidos los cuidados paliativos. En seguridad y vida sin violencia se protege la integridad y dignidad de la persona mayor, sin discriminación de ningún tipo.

9 Ver supra nota 4, 94.

10 Ver supra nota 4, I00-IOI. 
- Las medidas genéricas que pueden contribuir a la eficacia de los derechos humanos de los adultos mayores son fundamentalmente las que se indican a continuación:

En primer lugar, cabe mencionar el control de convencionalidad, que obliga a los jueces a aplicar la Convención Americana sobre Derechos Humanos y la jurisprudencia de la Corte Interamericana de Derechos Humanos, haciéndola primar por sobre la legislación nacional. De esta manera, dicho control permite superar los obstáculos o límites que pueda significar el derecho nacional al respeto y garantía de los derechos humanos ${ }^{11}$. Aun cuando escapa al propósito de este artículo, cabe señalar que el control de convencionalidad ha sido criticado tanto por su fundamentación jurídica como por su sentido y alcance ${ }^{12}$. Lo anterior es sin perjuicio de que la doctrina ${ }^{13}$ y la jurisprudencia actual reconocen y aceptan el ejercicio del control de convencionalidad. En este sentido, el Tribunal Constitucional ha declarado, al resolver un asunto sometido a su conocimiento, que «más significativa para este asunto es la jurisprudencia de la Corte Interamericana de Derechos Humanos» ${ }^{14}$. A su vez, en un reciente y relevante caso sobre cambio de nombre sin necesidad de intervención quirúrgica resuelto por la Corte Suprema, se puede apreciar cómo dicho control es ejercido por nuestro máximo tribunal al sostener que:

cabe recordar que la Corte Interamericana es el órgano a quien los Estados partes de la Convención Americana sobre Derechos Humanos encargaron la función de aplicación y de interpretación autoritativa del tratado. Por lo tanto, la interpretación que el tribunal regional le da a la Convención, incluso en la Opinión Consultiva recién mencionada, tiene carácter de autoritativa para Chile ${ }^{15}$.

11 Corte Interamericana de Derechos Humanos, Cuadernillo de Jurisprudencia de la Corte Interamericana de Derechos Humanos $\mathrm{N}^{\circ} 7$ : Control de Convencionalidad (20I7).

12 Ximena Fuentes, "El derecho internacional y el derecho interno: definitivamente una pareja dispareja”, Revista de Economía y Derecho I5 $_{5} \mathrm{n}_{4}^{\circ}$ (2007).

13 Constanza Núñez Donald, "Bloque de constitucionalidad y control de convencionalidad en Chile: avances jurisprudenciales", Anuario de Derechos Humanos II (20I5).

14 STC $2{ }_{4} 9^{2-20 I 3}$, del I7 de junio de $20 \mathrm{I}_{4}$, cdo. decimonoveno.

15 SCSJ sin referencia, del 29 de mayo de 20I8, cdo. octavo. Debido al deber de reserva, no se indica el rol de la causa ni el nombre de la recurrente. 
Por su parte, el principio pro homine sin duda también contribuye a dicha eficacia al facultar al Estado, y a todos sus órganos, a aplicar las disposiciones que sean más conducentes a la realización de los derechos humanos y que puedan estar recogidas en el derecho de un Estado parte; o el derecho internacional vigente con respecto a dicho Estado ${ }^{16}$.

Finalmente, cabe tener presente la obligación genérica que tiene el Estado según diversos tratados internacionales de adoptar las medidas legislativas o de otro carácter que fueren necesarias para hacer efectivos los derechos y libertades de las personas, entre ellas, las de los adultos mayores ${ }^{17}$.

- En cuanto a las medidas específicas como posibles soluciones o remedios respecto del incumplimiento de estos derechos, se indican las siguientes:

i) Lograr una armonización y coherencia en la regulación. La armonización de la legislación nacional con la regulación y estándares internacionales de protección y promoción de los derechos humanos de las personas mayores, y la coherencia en el sentido de evitar situaciones tales como consagrar la diferencia de edad para jubilar como se indicó anteriormente.

ii) Capacitar a los funcionarios y profesionales que deben vincularse directamente con los adultos mayores, especialmente en áreas tales como la salud.

iii) Crear una institucionalidad propia sobre la materia o fortalecer la existente.

iv) Aumentar los recursos económicos destinados a esta materia.

v) Lograr el reconocimiento constitucional expreso de este grupo vulnerable.

vi) Establecer impuestos en beneficio directo de los adultos mayores ${ }^{18}$.

Si observamos nuestro entorno y los propios antecedentes aportados por el Instituto Nacional de Estadística (INE), nos preguntamos, ¿por qué los adultos mayores siguen siendo un grupo vulnerable en nuestra sociedad? ¿Por qué la norma jurídica en favor

16 Guadalupe Romano, "Adultos mayores: Nuevos paradigmas del derecho y la seguridad social”, Letras Jurídicas I7 (2013): 3. El control de convencionalidad y pro homine son los nuevos paradigmas del derecho, señalan que se aplicarán no solo legislaciones internas. Éstas deberán complementarse e incluso suplirse o apoyarse en las convenciones internacionales de las que nuestro país sea parte.

17 Organización de Estados Americanos, Convención Americana sobre Derechos Humanos, "Pacto de San José”, 7-22 noviembre i969, art. 2. Ver también OEA, Convención Interamericana sobre la Protección de los Derechos Humanos de las Personas Mayores, art. 4; Naciones Unidas, Pacto de Derechos Civiles y Políticos, art. 2.2.

18 Gilbert Armijo, "Poder económico y discriminación etaria: la tutela del adulto mayor como derecho humano emergente”, Anuario de derecho constitucional latinoamericano XV (2009): 398 . 
del adulto mayor es ineficaz? La respuesta la encontramos sin duda en las razones antes detalladas. Si bien se han superado algunos de estos obstáculos, poco se va a avanzar si persiste la falta de conciencia que experimenta la sociedad y el Estado en relación con la situación actual de los adultos mayores. La demostración de esta afirmación se encuentra en que si bien existe un catálogo de derechos que protege de manera especial a los adultos mayores, dicha desprotección subsiste precisamente por el desconocimiento que existe tanto respecto de la realidad que viven los adultos mayores como del rápido crecimiento de la población de éstos últimos ${ }^{19} \mathrm{y}$ las consecuencias de diversa índole que ello genera tanto para las personas individualmente consideradas como para la sociedad en general. Este aspecto, relativo a la toma de conciencia, se desarrollará a continuación.

\section{Toma de conciencia como nueva obligación jurídica y fundamento de los derechos humanos del adulto mayor}

El fundamento teórico del problema planteado en este trabajo se encuentra en lo postulado tanto por la doctrina como en la práctica de Organizaciones Internacionales, y particularmente por la regulación contenida en el propio texto de la CIDHPM. En cada uno de dichos ámbitos, se declara la relevancia de la sensibilización, esto es, la toma de conciencia por parte de las personas y de los Estados acerca de los derechos humanos de los adultos mayores.

El artículo $3^{2}$ del capítulo V denominado «Toma de Conciencia» de la CIDHPM señala:

Los Estados Parte acuerdan: a) Adoptar medidas para lograr la divulgación y capacitación progresiva de toda la sociedad sobre la presente Convención. b) Fomentar una actitud positiva hacia la vejez y un trato digno, respetuoso y considerado hacia la persona mayor y, sobre la base de una cultura de paz, impulsar acciones de divulgación, promoción de los derechos y empoderamiento de la persona mayor, así como evitar el lenguaje e imágenes estereotipadas sobre la vejez. c) Desarrollar programas para sensibilizar a la población sobre el proceso de envejecimiento y sobre la persona mayor, fomentando la participación de ésta y de sus organizaciones en el diseño y formulación de dichos programas. d) Promover la inclusión de contenidos que propicien la compresión y aceptación de la etapa del envejecimiento en los planes y programas de estudios de los diferentes niveles educativos, así como en las agendas académicas y de investigación. e) Promover el reconocimiento de la experiencia, la sabiduría, la productividad y la contribución al desarrollo que la persona mayor brinda a la sociedad en su conjunto.

19 XinQi Dong, "Elder self-neglect: research and practice", Clinical Interventions in Aging 20I7 I2, (2017): 949 . 
La doctrina se refiere en diversos términos a la toma de conciencia haciendo mención a la falta de conciencia como un aspecto a considerar en la materia ${ }^{20}$ y a la necesidad de volver a valorar a los ancianos como en la antigüedad ${ }^{21}$. Se sostiene también que «el tema de la tercera edad es un tema invisible» ${ }^{22}$, o bien que es necesaria una definición sociocultural al respecto ${ }^{23}$.

\section{A. Fundamento de la toma de conciencia}

Tan relevante es el asunto de la toma de conciencia en materia de ancianidad, que la propia Asamblea General de las Naciones Unidas ${ }^{24}$ ha establecido el día I5 de junio de cada año como el día de la toma de conciencia del abuso y maltrato en la vejez, que busca llamar la atención sobre el trato a las personas mayores de la sociedad. En este día, en diversos Estados y organizaciones defensoras de la ancianidad se realizan actividades enfocadas en la importancia de prevenir la explotación financiera y maltrato del que son víctimas los ancianos, además de garantizar los derechos humanos de los adultos mayores.

Sin embargo, difícilmente en un solo día se podrá lograr la toma de conciencia necesaria para hacer efectiva la protección jurídica de los adultos mayores. Esta actividad no es más que una conmemoración a nivel mundial del repudio absoluto e inequívoco a los abusos a este grupo etario, pero marca un precedente respecto a la importancia que conlleva primeramente tomar conciencia de la situación de vulnerabilidad en la cual se encuentra la tercera edad, para luego conseguir efectividad en su resguardo y protección.

Otro antecedente que contribuye a fundamentar lo antes sostenido, y que resulta altamente novedoso, consiste en que en la CIDHPM regula en un título en particular la toma de conciencia indicando diversas medidas que deben adoptar los Estados al respecto ${ }^{25}$.

20 Ver supra nota 3, 234.

21 Fabiola Lathrop, "Protección jurídica de los adultos mayores en Chile", Revista Chilena de Derecho $3^{6} \mathrm{n}^{\circ} \mathrm{I}(2009): 77^{-78}$.

22 Ver supra nota $18,388$.

23 Ana Berta Aguilar y Linda de León Romero, Derechos Humanos y personas adultas mayores (Ciudad de Guatemala: Comisión Presidencial Coordinadora de la Política del Ejecutiva en Materia de Derechos Humanos, 20II), 2-3.

24 "Día Mundial de Toma de Conciencia del Abuso y Maltrato en la Vejez, I5 de junio", sitio de las Naciones Unidas, acceso el 28 de mayo de 20I8, http://www.un.org/es/events/elderabuse/.

25 Capítulo V de la CADHAM. 
Sin duda lo anterior es un cambio en la técnica de regulación internacional, ya que en los demás tratados sobre derechos humanos simplemente se hace una referencia a la toma de conciencia sin desarrollo alguno ${ }^{26}$. Este cambio refleja la relevancia de la toma de conciencia como una obligación determinante en relación a la eficacia de los derechos humanos del adulto mayor. Esto, a su vez, está en armonía con la declaración formulada por el Estado de Chile al ratificar la CIDHPM, en el sentido de recuperar el respeto al anciano y su valoración como un aporte y sustento para el desarrollo de una comunidad.

Otro aspecto que claramente da cuenta de la relevancia de esta obligación en la CIDHPM consiste en que no sólo se regula en un capítulo especialmente dedicado a la toma de conciencia, sino que también se consagran una serie de normas que conforman el contenido de tal obligación. Se destaca en dicho capítulo que los Estados deben desarrollar programas para sensibilizar a la población sobre el proceso de envejecimiento y sobre la persona mayor, fomentando la participación de ésta y de sus organizaciones en el diseño y formulación de dichos programas.

\section{B. ¿En qué consiste la toma de conciencia?}

La obligación de toma de conciencia comprende el deber de promoción de los derechos y empoderamiento de la persona mayor, así como evitar el lenguaje e imágenes estereotipadas sobre la vejez, de modo que los adultos mayores tengan una vida plena en todos los ámbitos, comprendiendo aspectos tales como el acceso a la atención de salud ${ }^{27} \mathrm{e}$ incluso temas que siguen siendo tabú como su vida sexual ${ }^{28}$. Esta dimensión de la obligación de toma de conciencia tiene particular relevancia en el ámbito jurídico ya que subsiste en la sociedad una clara discriminación hacia el adulto mayor al considerarlo no sólo una carga para la familia y la sociedad, sino que al mismo tiempo existe el prejuicio de que por el solo hecho de ser un adulto mayor se deja de ser capaz jurídicamente ${ }^{29}$.

Esta situación debe cambiar en el ámbito jurídico al estar obligado el Estado, en conformidad al artículo 7 de la CIDHPM, a reconocer el derecho de la persona mayor a tomar decisiones, a la definición de su plan de vida y a desarrollar una vida autónoma e indepen-

26 Organización de Estados Americanos, Convención Americana sobre Derechos Humanos, "Pacto de San José”, 7-22 noviembre I969, art. \&i. Ver también OEA, Convención Interamericana para Prevenir, Sancionar y Erradicar la Violencia contra la Mujer, "Convención de Belém do Pará”, art. 8(e).

27 Britta Baer et al., "The Right to Health of Older People", The Gerontologist 56 , supplement ${ }^{\circ}$ 2 (2016): 207 .

28 John Williams, "Intimate relationships between older people in institutional settings: Ageism, protection or fear?", Ethics, Medicine and Public Health $\mathrm{I}, \mathrm{n}^{\circ} 2$ (2015): $194-202$.

29 María Isolina Dabove, "Autonomía y vulnerabilidad en la vejez: respuestas judiciales emblemáticas”, Revista de Derecho Privado 34 (2018): 59. 
diente. Este cambio ya se ha efectuado en Argentina con la adopción de diversas medidas legislativas destinadas precisamente a garantizar el respeto a la capacidad de goce y de ejercicio de los adultos mayores, en el sentido de que ésta no se vea limitada por el solo hecho de tratarse de una persona mayor ${ }^{30}$.

En efecto, la toma de conciencia consiste en el deber del Estado de adoptar medidas para lograr la divulgación y capacitación progresiva de toda la sociedad sobre la presente Convención. Este aspecto se vincula directamente con el deber de promover el reconocimiento de la experiencia, la sabiduría, la productividad y la contribución al desarrollo que la persona mayor brinda a la sociedad en su conjunto. Sin duda este aspecto de la obligación se puede calificar como un pilar fundacional del deber de toma de conciencia, ya que se encuentra en perfecta armonía con la necesidad de rescatar el aprecio y valoración de los ancianos como ocurría en las culturas de la antigüedad y en los pueblos originarios, como se destaca en este trabajo.

\section{La toma de conciencia de los derechos de los adultos mayores como principio herme- néutico del ordenamiento jurídico}

La toma de conciencia, más que una obligación jurídica o legal, debe ser asimilada por cada Estado como un principio hermenéutico del ordenamiento jurídico reconocido en las propias normas constitucionales. En este sentido, debe interpretarse la Constitución y todas las normas del ordenamiento jurídico de acuerdo al sistema de derechos humanos que garantiza el derecho a la ancianidad ${ }^{31}$.

A este respecto, adquiere un rol absolutamente relevante el principio pro homine que implica que la interpretación jurídica siempre debe buscar el mayor beneficio para el hombre. Es decir, siempre debe acudirse a la norma más amplia o a la interpretación más extensiva cuando se trata de derechos protegidos, como en este caso de la ancianidad, y por el contrario, a la norma o a la interpretación más restringida cuando se trata de establecer límites a su ejercicio, como se contemplan en el artículo 29 de la Convención Americana sobre Derechos Humanos.

30 Ibid., 66. Ver además Sandra Huenchuan, “Los derechos de las personas mayores”, en Materiales de estudio y divulgación (Centro Latinoamericano y Caribeño de Demografía (CELADE), División de Población, Comisión Económica para América Latina y el Caribe (CEPAL), 20I3), 5, https://www. cepal.org/celade/noticias/documentosdetrabajo/8/51618/Derechos_PMayores_M2.pdf.

31 Humberto Henderson, "Los tratados internacionales de derechos humanos en el orden interno: la importancia del principio pro homine”, Revista Instituto Interamericano de Derechos Humanos 39: 29 . 
Lo anterior implica que los órganos del Estado, principalmente los tribunales de justicia, en quienes radica la tarea de garantizar el debido cumplimiento de la carta fundamental, apliquen de forma prioritaria los derechos fundamentales de las personas mayores ante una eventual transgresión de éstos. Así se logrará un resguardo efectivo de los derechos humanos de los adultos mayores, no tan solo en los establecimientos públicos, sino también en los establecimientos privados.

De esta forma, la toma de conciencia de los derechos humanos de este grupo etario debe constituir un principio fundamental en nuestro ordenamiento jurídico para la decisión judicial de un conflicto que involucre en cualquier medida la vulneración de sus derechos. En este sentido, los tribunales de justicia deben aplicar esta máxima de la toma de conciencia de forma similar al principio de interés superior del menor, el cual es un derecho especial de los niños, que se encuentra contenido en varias normas de rango constitucional, internacional e infraconstitucional, reconociéndose en todas ellas el interés superior del niño como criterio de toda acción pública o privada concerniente a una persona menor de dieciocho años ${ }^{32}$.

\section{Derecho Comparado}

En virtud de la aplicación de la toma de conciencia como principio hermenéutico, en determinados ordenamientos jurídicos se han creado normas destinadas exclusivamente a la protección de este grupo etario. Tal es el caso de la Ley Federal austríaca de los Adultos Mayores de 1998 (Bundesseniorengesetz), cuyo objetivo principal es asegurar la debida representación de las necesidades de los adultos mayores frente a los órganos de decisión a nivel federal, asegurar el asesoramiento, información y cuidado de estas personas por organizaciones de adultos mayores, entre otros ${ }^{33}$.

Asimismo, Suiza ha incorporado normas especiales dentro de su legislación general, puesto que no existe una ley federal que garantice los derechos de la tercera edad, pero sí regulaciones a nivel regional. Así, la Ley de promoción, coordinación y financiación de las actividades en favor de las personas mayores, ha cumplido el cometido de promover, coordinar y regular las actividades institucionales de las personas mayores ${ }^{34}$. Para el

32 Renée Marlene Rivero Hurtado, "El interés superior del niño en los procedimiento especiales seguidos ante los Tribunales de Familia" (Memoria para optar al grado de Licenciado en Ciencias Jurídicas y Sociales, Universidad de Chile), ıI7, http://repositorio.uchile.cl/bitstream/ handle/2250/ı2905/de-salgado_n.pdf?sequence=I\&isAllowed=y.

33 Christine Weidenslaufer Von Kretschmann et al., "Ministerios especiales y marco legal de protección del Adulto Mayor”, Asesorías Parlamentarias, Biblioteca del Congreso Nacional de Chile, 20I5, https://www.bcn.cl/obtienearchivo?id=repositorio/ro22I/2I $74_{4}^{2} / 4_{4} /$ ley\%20marco\%20 e\%2oinstitucionalidad\%20adulto\%2omayor_v3.pdf.

34 Ver supra nota 30, 26. 
cumplimiento de dicho cometido se otorgan subvenciones a las corporaciones públicas y privadas para adultos mayores, estableciendo programas e iniciativas a favor de los adultos mayores ${ }^{35}$.

En Noruega, los servicios sociales están contenidos en la legislación nacional, que es la Ley sobre salud y servicios de Cuidado Municipales de 20II, en donde se establece que son los municipios los responsables de proveer estos servicios a la población que reside dentro de su territorio. Por otra parte, en Suecia existe la Ley de Servicios Sociales, reformada en el año 2012 para permitir que los adultos mayores que han vivido juntos durante un período prolongado puedan seguir haciéndolo, incluso cuando uno de ellos tiene que trasladarse a una vivienda con asistencia o ELEAM. Finalmente, en Alemania existe la Ley sobre la capacitación de los cuidadores de personas mayores ${ }^{36}$.

En consecuencia, tanto las leyes descritas como el ordenamiento jurídico de nuestro país buscan resguardar los derechos de la tercera edad. La gran diferencia recae en que las citadas normas fueron fruto de la toma de conciencia por parte de los Estados y sus comunidades, atendiendo a la realidad existente de las personas mayores en sus países. Es decir, el éxito del catálogo de derechos fundamentales en favor de los adultos mayores en Austria, Suiza, Noruega, Suecia y Alemania se debe a que primeramente existió una toma de conciencia por parte de la comunidad y luego se legisló, atendiendo a las necesidades especiales y prioritarias de este grupo etario.

En este sentido, se destaca que no son meramente normas reglamentarias, sino que buscan reguardar un adecuado trato a la tercera edad, como por ejemplo lo pretende la ley de capacitación a cuidadores de personas mayores de Alemania, a diferencia del decreto I 4 del año 2010 del Ministerio de Salud de Chile, el cual solamente regula los requisitos formales que debe cumplir un ELEAM para su funcionamiento, pero carece de mención al trato especial que debe entregarse a sus residentes.

Entendiendo el contenido esencial de la obligación de toma de conciencia, resulta fundamental tener presente algunos antecedentes que reflejan la realidad de adulto mayor en Chile, y que se relacionan directamente con el problema propuesto, esto es, la ineficacia de los derechos humanos del adulto mayor. De este modo, en la medida en que se conozca la realidad de dicho grupo humano, se tome conciencia, o, como se ha dicho en doctrina, deje de ser un tema invisible, se contribuirá a consolidar el respeto a los derechos humanos del adulto mayor, y por consecuencia a su eficacia. Lo anterior se

\footnotetext{
35 Ver supra nota 33 .

36 Ver supra nota 33 .
} 
comprende desde el momento en que el respeto se entiende como el deber primario del Estado de no vulnerar ${ }^{37}$ los derechos humanos de los adultos mayores, lo que constituye evidentemente el punto de partida de la eficacia de toda norma.

3. Toma de conciencia como nueva obligación jurídica y necesidad imperante de su efectividad: deficiencias del sistema de seguridad social y establecimientos de larga estadía para el adulto mayor.

Es importante mencionar los indicadores que reflejan la realidad del adulto mayor en Chile, teniendo en consideración que a nivel latinoamericano es el tercer país con mayor cantidad de adultos mayores, luego de Uruguay y Cuba. Según el Instituto Nacional de Estadísticas, la tercera edad en el año I992 ascendía al 6.6\% de la población nacional, cifra que se ha acrecentado considerablemente, toda vez que según información del Censo realizado en el año 20I7, el porcentaje de la población de personas mayores de 60 años ha aumentado a un $\mathrm{Ir} \cdot{ }_{4} \%{ }^{38}$.

Chile se caracteriza por tener una tasa baja de natalidad y mortalidad, y en consecuencia, una esperanza de vida alta. Es por ello que el país cuenta con una población avejentada. Esto último puede ser atribuido a los avances tecnológicos, sanitarios y nuevos descubrimientos que se han experimentado en los últimos años, lo cual se ha traducido en un aumento de las expectativas de vida y, a su vez, en una disminución de la tasa de natalidad.

En este mismo orden de ideas, es importante considerar que cerca del $79 \%$ de las personas a partir de los 60 años se encuentran desempleadas ${ }^{39}$ a pesar de tener la capacidad y voluntad de continuar trabajando. De esta forma, el desempleo no sólo presenta un riesgo individual, sino también social cuando afecta a cantidades más o menos grandes de personas, debido a las repercusiones sociales que genera al desarrollo económico.

También es importante destacar que el 81\% de los adultos mayores están afiliados o son beneficiarios del sistema de salud público ${ }^{40}$, el cual es administrado por el Fondo

37 Cecilia Medina y Claudio Nash, Manual de Derecho internacional de los Derechos Humanos (Santiago: Centro de Documentación Defensoría Penal Pública, 2003), https://www.fundacionhenrydunant.org/images/stories/biblioteca/derechos_humanos/MEDINA_C._y_NASH_C._2003.Manual_de_Derecho_Internacional_de_los_DDHH.pdf.

Instituto Nacional de Estadísticas, Compendio Estadístico 2017 (Santiago: Instituto Nacional de Estadísticas, 20I8), http://www.ine.cl/docs/default-source/publicaciones/20I7/compendio-estadistico-20I7.pdf?sfvrsn=6.

39 Ver supra nota $3^{8 .}$

40 Ver supra nota 38. 
Nacional de Salud (FONASA). Si bien la cobertura que otorga este sistema es igualitaria para todos los afiliados-independiente del monto de la cotización y del tamaño del grupo familiar cubierto-tiene bastantes deficiencias, en atención a que los recursos que posee son escasos, las prestaciones médicas no son suficientes, y la demora o retraso en las prestaciones de los servicios genera una gran problemática, pues se trata de un grupo etario que necesita celeridad en las atenciones médicas debido a sus condiciones de salud. En efecto, el $62 \%$ de los adultos mayores son hipertensos, un $22 \%$ padece demencia, un I8\% sufre depresión y un i7\% sufre de la enfermedad de osteoporosis. Asimismo, el 8.5\% de los adultos mayores tiene deterioro del sistema cognitivo entre los 60 y los 75 años. Sobre los 85 años de edad, este indicador se empina sobre $40 \%$ y el deterioro es hasta 13 veces mayor en personas sin escolaridad ${ }^{41}$.

Estudios Nacionales del Ministerio de Desarrollo Social ${ }^{22}$ indican que cerca del $25 \%$ de las personas de 60 años y más tienen dificultades para realizar por sí mismos las actividades de la vida cotidiana. Es por ello que al menos el ${ }_{4} \%$ de los adultos mayores se encuentran postrados, cifra que constituye el r\% de la población total de adultos mayores. Si bien el $86 \%$ de las personas con dependencia tiene vivienda propia, sucede que no logran adaptar sus condiciones de habitabilidad en atención a sus dificultades funcionales o requerimientos de salud.

Por otra parte, además de las cifras ya mencionadas, existen a su vez dos aspectos que dan cuenta de la falta de toma de conciencia sobre la realidad y los derechos de los adultos mayores. El primero de ellos dice relación con el maltrato del cual son objeto algunos ancianos, y el segundo se refiere a la situación de abandono en que se encuentra el adulto mayor.

Respecto al primer aspecto, se puede señalar que el maltrato se manifiesta a través de distintas formas, como son las discriminaciones arbitrarias existentes por edad, el abandono en los ELEAM, la violencia física y psicológica ejercida contra ellos, la negligencia, además del maltrato estructural o social y el abuso patrimonial. Estos comportamientos de maltrato hacia el adulto mayor se acrecientan en los ELEAM clandestinos que se abren por particulares que no cumplen con las condiciones mínimas de una calidad de vida digna y que por ello carecen de autorización sanitaria. En relación al segundo aspecto, la situación de abandono del adulto mayor en ELEAM por parte de sus familiares es crítica. A saber, $13 \%$ de las personas con dependencia severa no es visitado nunca por sus familiares ${ }^{43}$.

41 Ver supra nota $3^{8 .}$

42 Ministerio de Desarrollo Social, Informe de Política Social 2012, I86-205, http://www.ministeriodesarrollosocial.gob.cl/ipos-20I2/media/ipos_20I2_pp_I86-205.pdf.

43 Ver supra nota $3^{8 .}$ 
A continuación se analizarán dos grandes temáticas relacionadas con las deficiencias del sistema de seguridad social y los ELEAM, a modo de ejemplificar y evidenciar la necesidad de consagrar la toma de conciencia, no sólo como una obligación jurídica, sino como fundamento principal de la efectividad de los derechos humanos de los adultos mayores. De esta manera se contribuye a garantizar a los adultos mayores un trato digno y sin discriminaciones arbitrarias, como se ha logrado en otros Estados más avanzados en esta materia ${ }^{44}$.

\section{A. Seguridad Social}

En este sentido, la sociedad debe tener la conciencia pública de que las organizaciones privadas de beneficencia no han sido suficientes para abarcar todos los riegos y contingencias sociales que ocurren en la vida de las personas. En consecuencia, es pertinente destacar la importancia de la Seguridad Social, que ha sido definida por la Organización Internacional del Trabajo (OIT) como un Derecho Humano, y que se entiende en un sentido amplio como «la protección que la sociedad proporciona a sus miembros, mediante una serie de medidas públicas, contra las privaciones económicas y sociales que, de no ser así, ocasionarían la desaparición o una fuerte reducción de los ingresos por causa de enfermedad, maternidad, accidente del trabajo o enfermedad laboral, desempleo, invalidez, vejez y muerte; y también la protección en forma de asistencia médica y de ayuda a las familias con hijos» ${ }^{45}$.

La Seguridad Social ha sido considerada como un derecho humano básico en la Declaración de Filadelfia de la OIT de I9łł y en su Recomendación sobre la Seguridad de los medios de vida $\mathrm{N}^{\circ} 67$ de i94ł. Este derecho está confirmado en la Declaración Universal de los Derechos Humanos, 1948 , y en el Pacto Internacional sobre Derechos Económicos, Sociales y Culturales, $\mathrm{I} 966$.

En Chile, el Derecho a la Seguridad Social fue reconocido como Garantía Constitucional por primera vez en la Constitución de 1925, y actualmente se encuentra garantizado por la Constitución Política en el artículo ig, número I8. Respecto a la acción del Estado en esta materia, dicho artículo, en su inciso $2^{\circ}$, señala que aquella «estará dirigida a garantizar el acceso de todos los habitantes al goce de prestaciones básicas uniformes, sea que se otorguen a través de instituciones públicas o privadas», y establece como deber del Estado supervigilar su adecuado ejercicio.

44 Håkan Jonson y Tove Harnett, "Introducing an Equal Rights Framework for Older Persons in Residential Care", The Gerontologist 56, $\mathrm{n}^{\circ} 5$ (20I6): 800-80I.

45 Corporación de Investigación, Estudio y Desarrollo de la Seguridad Social (CIEDESS), "La Seguridad Social en Chile”, acceso el 30 de julio, 20I8, http://www.ciedess.cl/6or/w3-propertyname-5or.html. 
En consecuencia, se debe entender que la vejez forma parte de una de las ramas de la Seguridad Social con amplio reconocimiento internacional. Es más, el Convenio de la Organización Internacional del Trabajo relativo a la norma mínima de seguridad social regula en su parte $\mathrm{V}$ las prestaciones de vejez en los artículos i5 y siguientes ${ }^{46}$. Sin embargo, éste no ha sido ratificado por Chile.

A pesar de ello, en nuestro país se garantizan las pensiones de vejez, lo cual es uno de los beneficios previsionales consagrados en el D.L. $\mathrm{N}^{\circ} 3.500$ de 1980 , y que consiste en el derecho que tienen los afiliados al sistema a obtener una pensión una vez que hayan cumplido con la edad legal exigida para tales efectos, a saber, $6_{5}$ años de edad para los hombres y 60 años de edad para las mujeres. Cabe señalar que pensionarse es un derecho y no una obligación, por lo tanto, los afiliados que hayan cumplido la edad establecida para pensionarse por vejez y que continúen trabajando como dependientes podrán seguir cotizando de manera voluntaria en la Administradora de Fondos de Pensión (AFP), con el objeto de aumentar la pensión que reciban.

Las pensiones de vejez se determinan en función del saldo efectivo de la cuenta de capitalización individual, de las expectativas de vida del afiliado y de los miembros de su grupo familiar que sean o puedan ser beneficiarios de pensión de sobrevivencia. Sin embargo, actualmente en Chile el dinero ahorrado en la cuenta de capitalización individual depende de la acumulación de fondos que cada trabajador debe hacer individualmente con tal objeto a lo largo de su vida laboral activa, ahorro que será capitalizado con los correspondientes intereses, es decir, con la rentabilidad que obtenga el fondo de pensiones. Lamentablemente, no todos los trabajadores al final de su vida útil logran acumular una cantidad de dinero que les permita mantenerse dignamente en la vejez.

En consecuencia, el Estado, a través de la Ley $20.255^{47}$, ha introducido reformas sustanciales al sistema de pensiones, principalmente en lo referido a dar cobertura a los sectores más pobres de la sociedad, creando un sistema de pensiones solidarias. Este sistema de pensiones solidarias otorga a la población más vulnerable del país, aun cuando no haya cotizado o tenga muy pocos fondos en la AFP, un financiamiento estatal para sus pensiones a través del Pilar Solidario, cuyo objetivo fundamental es la prevención de la pobreza en la tercera edad. En general, el Pilar Solidario otorga pensiones básicas de vejez e invalidez a las personas que no hayan podido cotizar en AFP, y un complemento solidario para los que sí lograron acumular saldo cuando éste es demasiado bajo o insuficiente.

46 Organización Internacional del Trabajo, Convenio sobre la seguridad social (norma mínima), I952 (núm. Iо2) (Cıо2); AH Abashidze y VS Malichenko, "International and National Legal Mechanisms of Ensuring Social Justice for the Elderly", Advances in Gerontology $4, \mathrm{n}_{4}^{\circ}\left(20 \mathrm{I}_{4}\right): 222$.

47 Ley 20.255, del I7 de marzo de 2008, que establece reforma previsional. 
El Pilar Solidario cumple un rol fundamental en la prevención de la pobreza y tiene un efecto sustancial en suficiencia y equidad. Sin embargo, para gozar de este beneficio es requisito fundamental que la persona tenga 65 años de edad. En consecuencia, si una mujer decide jubilar a los 60 años y no tiene saldo en su cuenta de capitalización individual, porque no ha trabajado nunca o su monto es mínimo, tendrá que esperar hasta los 65 años para optar a una pensión solidaria básica de vejez, la cual a partir del $\mathrm{I}^{0}$ de julio del año 2017 asciende a \$104.646 pesos. Otra opción consiste en solicitar al Estado el aporte previsional solidario de vejez, que es un complemento monetario mensual de cargo fiscal que incrementa las pensiones base inferiores a \$3०9.23r pesos a través de un aporte que aumenta el monto de la pensión final con el objetivo de mejorar la suficiencia de los beneficios previsionales. Del mismo modo, esta mujer deberá esperar hasta que cumpla los 65 años de edad para recibir el bono por hijo, el cual es el beneficio de cargo fiscal que incrementa el monto de la pensión de la mujer a través de la entrega de un bono por cada hijo nacido vivo o adoptado. Este monto de dinero que el Estado entrega a las mujeres con hijos cuando cumplen $6_{5}$ años de edad se deposita en su cuenta de AFP con el fin de incrementar su pensión, en el caso de haber sido madres.

En consecuencia, si bien en la práctica existen pensiones asistenciales, la norma o el beneficio se vuelve ineficaz respecto de la mujer entre los 60 y los 65 años de edad, ya que no existe beneficio social que pueda solicitar al Estado para subsistir durante esos 5 años y sólo le queda recurrir a la caridad de los privados.

\section{B. Establecimientos de Larga Estadía para el Adulto Mayor (ELEAM)}

Los ELEAM o Residencias Colectivas de Larga Estadía para Adultos Mayores, conocidos popularmente como Hogares de Ancianos, son aquellos en que residen personas de 60 años o más, que, por diversos motivos, requieren de un medio ambiente protegido y de cuidados diferenciados. Los ELEAM, debido a la importante función que cumplen dentro de nuestra sociedad, se rigen por el Reglamento de Establecimientos de Larga Estadía para Adultos Mayores, Decreto Supremo $\mathrm{N}^{\circ} \mathrm{I}_{4}$ del año 2010.

En todo caso, la situación de abandono del adulto mayor en ELEAM por parte de sus familiares se manifiesta a través de dos grandes problemas. El primero de éstos es que en Chile no existe una institución del Estado similar a estos establecimientos, lo cual se traduce en una omisión grave, puesto que en países en que existe un efectivo y eficiente amparo a la tercera edad, tales como Austria, Noruega, Suecia y Suiza ${ }^{48}$, el legislador expresamente encomienda este cometido al Estado. En la actualidad existen establecimientos religiosos que, si bien suplen en alguna medida esta necesidad, son de muy difícil acceso debido a sus largas listas de espera; y respecto a los establecimientos

48 Ver supra nota 33 . 
particulares, que son la mayoría, uno de los grandes problemas que se presenta cuando los adultos mayores son abandonas por sus familiares se relaciona con que sus propietarios deben asumir responsabilidades y gastos ajenos a ellos, no sabiendo cómo enfrentar dicho acontecimiento.

El segundo problema posible de evidenciar es que la SEREMI de Salud-organismo encargado de fiscalizar dichos establecimientos, en conformidad al Código Sanitario-es la principal testigo de las inhumanas condiciones en que se encuentran sus residentes, sobre todo en establecimientos clandestinos. Frente a estas situaciones, la autoridad sanitaria tiene el deber de clausurar inmediatamente dichos establecimientos. Pero si no existe una institución del Estado que pueda acoger a la tercera edad, ¿qué se hace con estos ancianos abandonados? Ésta es una difícil pregunta que nos deja atados de actuar, puesto que por un lado, como se ha dicho, existen grandes listas de espera en establecimientos reconocidos, por lo que es muy difícil su ingreso, y por otro lado, si se clausuran dichos establecimientos clandestinos, los ancianos residentes quedarían en la calle. En efecto, en ambas situaciones la tercera edad queda en estado de vulnerabilidad de sus derechos fundamentales.

Nuestro ordenamiento jurídico consagra el principio de subsidiariedad en las bases de la institucionalidad de nuestra Carta Fundamental. Este principio desde una perspectiva positiva implica que el Estado debe ejecutar una labor orientada al bien común cuando advierte que los particulares no la realizan adecuadamente, ya sea por imposibilidad o por cualquier otra razón. En la problemática en comento queda de manifiesto que es el Estado el último responsable de garantizar el derecho a los cuidados a largo plazo establecidos en la CIDHPM, en conformidad a su artículo i2, siendo éste uno de los derechos fundamentales inéditos que se crea a la luz de este instrumento internacional. En este sentido, atendiendo que los establecimientos sociales o religiosos no tienen vacantes disponibles, y los establecimientos particulares seguros exceden los valores que pueden pagar los adultos mayores en razón a las bajas pensiones que reciben, es el Estado quien debe crear establecimientos dignos y de calidad para todos los adultos mayores de nuestro país que no puedan subsistir por sí mismos. La falta de recursos no puede justificar el trato indigno del cual son víctimas cientos de adultos mayores en Chile. 


\section{Conclusión}

Existe una regulación normativa que busca amparar la situación actual en la que se encuentran los adultos mayores a nivel nacional e internacional, pero que en la realidad no se lleva a cabo en su totalidad. Considerando los antecedentes antes mencionados y observando nuestro entorno, se advierte que aún existen personas mayores con enfermedades, sin recursos económicos, abandonados y viviendo en la miseria, evidenciando así una realidad espeluznante. Las normas que buscan reguardar a los adultos mayores son válidas y existe un catálogo de derechos, pero estas normas son ineficaces, porque seguimos observando a este grupo etario como un sector vulnerable de la población y menospreciándolos como seres humanos.

En consecuencia, el problema principal de la la ineficacia de los derechos humanos de los adultos mayores encuentra su fundamento último en la falta de toma de conciencia tanto de la realidad que viven los adultos mayores, como de sus intereses y necesidades. La toma de conciencia implica observar y darse cuenta de la situación actual de este grupo etario. Es un proceso complejo, pero necesario para cambiar nuestra realidad y así darles eficacia a las normas establecidas a su favor.

La falta de sensibilización o toma de conciencia por parte del Estado y de la sociedad es el principal motivo de la ineficacia de las normas jurídicas tendientes a resguardar a la tercera edad. Si no se comprende la magnitud del problema, difícilmente se logrará un cambio poderoso y efectivo en el trato que merece este especial grupo etario. Así se destaca que, si no se cumple con la obligación jurídica de toma de conciencia, las diversas medidas que se puedan adoptar en pro de la eficacia de los derechos humanos de las personas adultas resultan ser simplemente paliativas que no logran sustentarse en el tiempo.

En este artículo no se pretende desincentivar iniciativas positivas, tales como la figura del "Defensor Mayor", anunciada recientemente por el Gobierno del Presidente Sebastián Piñera durante el día del buen trato del adulto mayor, cuyo rol es fortalecer la promoción y protección de los derechos de las personas mayores a través de un abogado especialista en estas materias. Asimismo, tampoco se pretende subestimar las actuaciones del Servicio Nacional del Adulto Mayor, cuya misión es fomentar el envejecimiento activo y el desarrollo de servicios sociales para las personas mayores. Por el contrario, a lo que se aspira con este arículo es que, a través de la toma de conciencia de la realidad de este grupo etario, se adquiera un efectivo respeto a los derechos fundamentales de las personas mayores, se valore y se aprecie el aporte que pueden realizar a la sociedad, entre otros objetivos. 
El desafío actual de la situación chilena consiste en lograr que la toma de conciencia se refleje en cinco actuaciones esenciales e inmediatas: I) adoptar medidas que logren una capacitación progresiva de toda la comunidad sobre los derechos y garantías de los adultos mayores; 2) fomentar una actitud positiva hacia la vejez y el trato digno, evitando imágenes e ideas estereotipadas de este grupo etario; 3) desarrollar programas prolongados en el tiempo que permitan sensibilizar a la población sobre el proceso de envejecimiento y sobre la persona mayor; 4 ) promover la inclusión de temáticas que permitan comprender y aceptar la etapa de envejecimiento en programas académicos y de investigación; 5) promover la valoración de la experiencia, sabiduría y productividad de este grupo etario, haciéndolo parte de decisiones más certeras en el quehacer diario.

Finalmente, cabe destacar que la toma de conciencia es un trabajo que debe desarrollarse día a día, en el cual debe existir una participación activa de todos los miembros de la sociedad. En la medida en que nos comprometamos con este cometido, el catálogo de derechos fundamentales a favor de la tercera edad será efectivo, y paulatinamente mejorará la calidad de vida de los adultos mayores de nuestro país. $\square$ 


\section{BIBLIOGRAFÍA}

- Abashidze, AH. y Malichenko, VS. "International and National Legal Mechanisms of Ensuring Social Justice for the Elderly". Advances in

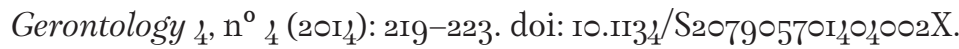

- Aguilar, Ana Berta y de León Romero, Linda. Derechos Humanos y personas adultas mayores. Ciudad de Guatemala: Comisión Presidencial Coordinadora de la Política del Ejecutiva en Materia de Derechos Humanos, 20II. http://www.corteidh.or.cr/tablas/r29529. pdf.

- Armijo, Gilbert. "Poder económico y discriminación etaria: la tutela del adulto mayor como derecho humano emergente". Anuario de derecho constitucional latinoamericano XV (2009): $387^{8-40}$. http:// www.corteidh.or.cr/tablas/r23538.pdf.

- Baer, Britta, Bhushan, Anjana, Abou-Taleb, Hala, Vasquez, Javier y Thomas, Rebekah. "The Right to Health of Older People". The Gerontologist 56 , supplement $\mathrm{n}^{\circ}{ }_{2}$ (2016): 206-217. doi:Io.Io93/geront/ gnwo39.

- Consejo de Derechos Humanos de las Naciones Unidas. Informe resumido de la consulta sobre la promoción y protección de los derechos humanos de las personas de edad. Informe de la Oficina del Alto Comisionado de las Naciones Unidas para los Derechos Humanos. I de julio de 20r3. https://documents-dds-ny.un.org/doc/ UNDOC/GEN/Gi3/I53/29/PDF/Gr3I5329.pdf.

- Corporación de Investigación, Estudio y Desarrollo de la Seguridad Social (CIEDESS). "La Seguridad Social en Chile". Acceso el 30 de julio, 20I8. http://www.ciedess.cl/6or/w3-propertyname-5or.html.

- Corte Interamericana de Derechos Humanos. Cuadernillo de Jurisprudencia de la Corte Interamericana de Derechos Humanos $\mathrm{N}^{\circ}$ 7: Control de Convencionalidad (20I7). http://www.corteidh.or.cr/ tablas/r33825.pdf. 
- Dabove, María Isolina. "Autonomía y vulnerabilidad en la vejez: respuestas judiciales emblemáticas". Revista de Derecho Privado, $\mathrm{n}^{0}$ 34. (2018): 53-85. doi: 10.1860I/or234366.n34.०3.

- Dong, XinQi. "Elder self-neglect: research and practice". Clinical Interventions in Aging I2 (2017): 949-954. doi: 10.2147/CIA.Sro3359.

- Fuentes, Ximena . "El derecho internacional y el derecho interno: definitivamente una pareja dispareja”. Revista de Economía y Derecho I5, $\mathrm{n}_{4}^{\mathrm{o}}(2007): 2 \mathrm{I}-35$.

- Huenchuan, Sandra. "Los derechos de las personas mayores". en Materiales de estudio y divulgación. Centro Latinoamericano y Caribeño de Demografía (CELADE), División de Población, Comisión Económica para América Latina y el Caribe (CEPAL), 20I3. https:// www.cepal.org/celade/noticias/documentosdetrabajo/2/43682/ Modulo_I.pdf.

- __ "Un paso adelante para los Derechos Humanos. La protección de las personas mayores en las Américas". Anuario de Derechos Humanos I2 (2016): 225-236. doi:10.5354/०718-2279.2016.42751.

- Perspectivas globales sobre la protección de los derechos humanos de las personas mayores, 2007-2013. Naciones Unidas, Comisión Económica para América Latina y el Caribe (CEPAL), 20r3. https:// www.cepal.org/es/publicaciones/35929-perspectivas-globales-la-proteccion-derechos-humanos-personas-mayores-2007-2013.

- Jonson, Håkan y Harnett, Tove. "Introducing an Equal Rights Framework for Older Persons in Residential Care". The Gerontologist 56 , $\mathrm{n}^{\circ}{ }_{5}$ (2016): 800-806. doi.org/Io.Iog3/geront/gnvo39.

- Lathrop, Fabiola. "Protección jurídica de los adultos mayores en Chile”. Revista Chilena de Derecho 36, n I (2009): 77-II3.

- Núñez Donald, Constanza. "Bloque de constitucionalidad y control de convencionalidad en Chile: avances jurisprudenciales". Anuario de Derechos Humanos II (20I5): I57-I6g. doi: I0.5354/o718-2279.20I5.37497.

- Romano, Guadalupe. "Adultos mayores: Nuevos paradigmas del derecho y la seguridad social”. Letras Jurídicas 17 (2013). http:// servicios.cuci.udg.mx/letrasjuridicas/index.php/letrasjuridicas/ article/view/202/200. 
- Squella Narducci, Agustín. Introducción al Derecho. Santiago: Editorial Jurídica de Chile, 2000.

- Weidenslaufer Von Kretschmann, Christine, Trufello García, Paola, Loiseau, Virginie, Hafner, Annette. "Institucionalidad específico y marco legal de protección del Adulto Mayor. Legislación y Experiencia Comparada”. Asesorías Parlamentarias. Biblioteca del Congreso Nacional de Chile, 20I5. https://www.bcn.cl/ obtienearchivo?id=repositorio/Io221/21742/4/ley\%2omarco\%20e\%20 institucionalidad\%20adulto\%20mayor_v3.pdf.

- Williams, John. "Intimate relationships between older people in institutional settings: Ageism, protection or fear?”. Ethics, Medicine and Public Health I (2015): 194-202. doi: 10.1016/j.jemep.2015.03.010. 